\title{
Organizational Culture Challenges of Adopting Big Data: A Systematic Literature Review
}

\author{
Trygve Åse Lunde ${ }^{1}$, Atilla Paul Sjusdal ${ }^{1}$ and Ilias O. Pappas ${ }^{1,2}$ [0000-0001-7528-3488] \\ ${ }^{1}$ University of Agder, Kristiansand, NO-4639, Norway \\ ${ }^{2}$ Norwegian University of Science and Technology, Trondheim, NO-7491, Norway \\ ilias.pappas@uia.no
}

\begin{abstract}
The interest of adopting big data (BD) in organizations has emerged in recent years. Even though many organizations have attempted to adopt BD, the benefits gained by this investment has been limited, and organizations struggle to fully utilize the potential of BD. There has been done several studies on the different challenges and benefits that may occur during the process of adopting and using BD. One major factor that has been discussed in the literature to overcome such challenges has been organizational culture. This paper aims to provide a systematic literature review that reports the organizational culture's impact on BD adoption through the lens of different cultural dimensions. This paper identifies the different dimensions of organizational culture and dives into the specific challenges and potential strategies/techniques to combat these challenges. By reviewing these papers, we ended up with identifying four dimensions of organizational culture in the context of BD. The result of this paper aims to help practitioners and researchers to understand and combat the specific challenges surrounding organizational culture when adopting BD.
\end{abstract}

Keywords: Big data, organizational culture, data-driven culture, systematic literature review

\section{Introduction}

Over the last decade, the business world has been shaken by a remarkable wave of digital disruption that is impacting the way organizations compete [1]. This is pushing today's societies into a continually expanding digitalized world, where information and knowledge gets available to more and more people. The different digital media platforms, digital services and technologies is changing the way societies are organized, and how their members interact with each other. Organizations are starting to realize that the massive amounts of data that are being generated, can provide them with a competitive edge [2]. Big data, however, are also challenging existing modes of business and well-established companies [2]. Solving this so that these technologies can be incorporated into competitive strategies has been a goal of academics and practitioners. The focus however has been on the technical aspect of $\mathrm{BD}$, and less on the organizational changes [3]. This is causing organizations to have problems utilizing BD to 
improve their organizational performance [4], as it requires them to overcome several challenges, one of them being the organizational culture [5].

Organizational culture in relation to BD has been studied in the literature. Many of the papers highlight that organizational culture has a critical role in the success of $\mathrm{BD}$ initiatives and is often the main reason why BD initiatives fails, rather than technological factors [6][7]. The primary focus for most of the papers has been on how organizations can handle the challenges and barriers that come with BD adoption, and how to gain the most from this adoption. This is where organizational culture is mentioned as being one of the most important factors for succeeding with BD adoption. Management support is also mentioned as an important component in relation to organizational culture since it requires training and new managerial skills.

BD adoption is not only technical platforms and skills but will also influence the organizational culture [8]. Thiraton et al. [9] specifically studied different factors that impacted big data analytics (BDA) with a focus on analytic culture and how much of an impact it had.

Organizational culture has a strong impact on various aspects of an organization, such as strategy, structure, and processes. Many of the obstacles in relation to $\mathrm{BD}$, are more than likely to be related to organizational culture and not to data or technology [10]. This is also demonstrated in recent literature, where organizational culture has a critical role in the success of BD initiatives and is often the main reason why BD initiatives fails, rather than the technological factors [6][7].

The literature exposed a need for knowledge surrounding organizational culture in the field of BD. By doing a systematic literature review on the topic, it could potentially bring a positive impact to the field of BD.

This paper is organized as follows. Firstly, it will present the research background where the different dimensions/concepts from BD and organizational culture will be defined. Secondly, it discusses the research method. Lastly, it presents and discusses the research findings.

\section{Background}

The goal of a BD investment is to enhance the organization's ability to make better decisions along with better decision execution processes. Making informed decisions is one of the building blocks of organizational success [11]. All organizations that have put effort and investment in BD should be able to harvest results via gaining a competitive advantage and improving their performance. However, to fully harness the full potential of big data, the organization also must develop, nurture and maintain an organizational culture that will have positive impact on $\mathrm{BD}$ [12]. This is important when around $80 \%$ of businesses have failed to implement their BD strategies successfully [11] and regardless of their efforts, many organizations have not been able to realize the potential of $\mathrm{BD}$ in an effective manner [13].

The notion of organizational culture is highly complex and hard to understand and describe. Definitions regarding organizational culture have been explained several times by management scholars, yet there is no consensus on a single definition [14]. 
Even though there are several definitions for organizational culture, it is often described in two different ways. Some suggest that organizational culture encompasses most of the areas of an organization, while others look at organizational culture as a glue that keeps an organization together [15][16]. Yet organizational culture is often defined as:" a collection of shared assumptions, values, and beliefs that is reflected in its practices and goals and further helps its members understand the organizational functions" [17][18].

One aspect of organizational culture in the context of BD is often referred to as organizational learning, which is a critical aspect of BD initiatives [3][14][19]. Gupta \& George [14] defines organizational learning as: "a process through which firms explore, store, share and apply knowledge". Organizational learning opens the opportunity for employees to exploit the existing knowledge and expand their knowledge to adopt and compete in a continuously changing market [2]. By reconfiguring the resources according to the changes in the external environment, the organizations have better odds of having a sustained competitive advantage [20]. To gain a competitive advantage, the intangible resources, such as data-driven culture and organizational learning is just as important as the tangible resources, where the insights extracted from data are ought to be valued and acted upon [14]. Developing a data-driven culture requires the top management to select the strategy and design the organization structure according to the desired values and norms [10]. Additionally, organizations are more likely to use business analytics and big data effectively with a data-driven culture, where the leadership and employees understand the important and critical role of data in their organization [21][22]. Further, Alharthi et al. [10] argues that many barriers related to BD is cultural, rather than technological. The lack of management's understanding of the value of BD may result in organizational resistance to $\mathrm{BD}$, leading to the resistance to the development of a data-driven cultural and gaining the potential competitive advantage it carries.

Previous studies argue that $\mathrm{BD}$ itself does not give a competitive advantage, but rather developing capabilities that competitors struggle to match [14]. Creating BDA capabilities, a combination of certain tangible, human and intangible resources can lead to superior firm performance. Studies also examine technology management and suggest that it is related with $\mathrm{BD}$ decision making, while technological competency is required to facilitate the use of $\mathrm{BD}$ for analysis [6]. One of the defining features of BD is the unsuitability of existing processing techniques and how to store large amount of data to generate value from BD technology [23]. To generate value from BD and the technology used, organizations must develop or acquire analytic capabilities, which allows the organization to transform data to valuable information [9]. Dubey et al. [18] argues that organizational capability development is needed to fully exploit analytic capabilities. Furthermore, the complementary capability development highly depends on the organizational culture. Even though the analytic and technical capabilities are developed within an organization, executives still struggle to understand and implement $\mathrm{BD}$ strategies effectively [9]. One of the bigger challenges for managing BD, may not be the technology or data itself, but rather to use the human capital and culture to support these strategies [24]. 


\section{$3 \quad$ Research method}

Reviewing previous literature is a key element in any academic work. The benefits of performing a systematic literature review is that it provides a framework/background in order to position new research activities [25]. There are an overwhelmingly amount of literature regarding every topic out there and reviewing all the literature concerning this topic will be difficult, but by using a systematic approach to review the literature, the level of quality will be higher and the process of reviewing the literature in a good manner will be achievable. By using such approach, it makes it less likely that the chosen literature is biased [25].

There are several ways of conducting a systematic literature review. Our literature review is based on the guidelines presented by Webster \& Watson [26]. The process that has been used in this review is documented in the next section. The main objective of this study is to answer the following research question:

RQ: What is the current status regarding the impact of organizational culture on big data and analytics adoption?

When searching for relevant literature regarding our research question, we used seven databases. The databases we used were Wiley Online Library, SAGE journals, Taylor \& Francis Online, Emeraldinsight, IEEE Xplore digital library, Sciencedirect and Scopus. By differentiating the use of databases, we ensure to obtain the literature required to perform a proper systematic literature review. In these databases, we used several search strings which included synonyms and other phrasing of the constructs used in the research question. The keywords used in the searches were not limited to title or abstract, but rather everywhere in the article. The phrases we decided to use were carefully selected by looking at different possibilities and synonyms that might increase the search result. This resulted in four different search strings which is presented in Table 1.

By using the different set of search strings presented in Table 1, we ended up with a plethora of gathered literature. The search strings we used and the total amount of articles for each search string and the number of articles that were used in systematic literature review.

Table 1. Search strings and results

\begin{tabular}{|l|l|l|}
\hline Search strings & Results & Used articles \\
\hline "Analytic Culture" & 384 & 1 \\
\hline "Big Data" AND "Organizational Culture" & 1455 & 10 \\
\hline "Data Analytics" AND "Organizational Culture" & 817 & 1 \\
\hline "Data-Driven Culture" & 218 & 7 \\
\hline Total results & 2874 & 19 \\
\hline
\end{tabular}




\subsection{Selection process}

The literature was manually reviewed to conclude the relevance to this study by reviewing the title, abstract and full text and compare it to our research question. Therefore, we developed some inclusion and exclusion criteria for this review to assist us in evaluating the relevance of the articles to our research question and literature review. The articles that met the requirements in the inclusion criteria were used in the primary studies. The articles that included the exclusion criteria, were not used in the study. The inclusion and exclusion criteria are shown in Table 2.

Table 2. Inclusion \& Exclusion criteria

\begin{tabular}{|l|l|}
\hline Inclusion criteria & Exclusion criteria \\
\hline & Mentioning terms, but not related to our \\
Conference proceedings & RQ \\
\hline Focus on big data and relates to the RQ & Not peer-reviewed journals/conferences \\
\hline Peer-reviewed journal & Books \\
\hline
\end{tabular}

The approach for gathering the literature were based on a concept centric approach, were we reviewed the concepts of the articles in relations to our research question. By using this approach, we eliminated several articles that had the search strings in their title or abstract but were not relevant to our study because of the wide range of research regarding these topics. We did not exclude "lower quality" journals because literature that is published in journals assumed to have less quality, may have established some new research that might assist this research in a positive manner. Watson \& Webster [26] states that a literature review should not confined to one research methodology, one set of journals or one geographic region. By having this approach, we manage to look at literature that might not be published in the "top" journals but might have some contribution to the topic of interest.

By reviewing the titles of these articles, we looked at the relevance they had to our topic and research question. In this phase, we were open to articles that were not directly connected to our research question and accepted them when they were somewhat relevant. This was to ensure that we did not exclude any articles too soon.

In addition to the 19 articles we found, we rounded up the process by searching Google Scholar to see if there were any papers that were relevant to our systematic literature review that might not show up in the other searches. In this search process, we managed to find two papers that had a direct connected to our topic that we decided to include in this paper. The articles we included were Mikalef et al. [3] and Pappas et al. [2].

\section{$4 \quad$ Findings}

The findings of this literature review are presented in two parts. The first part is presented quantitatively. The second part is analyzing and interpreting the data from the selected studies to answer the research question. The main concepts discussed in the articles are 
BD and organizational culture. The different dimensions of both concepts are being discussed in the literature, however the level of focus on each paper varies. Most of the papers mentions organizational culture as an important factor in BD adoption, but few of them have organizational culture as a primary focus. The remaining papers that does, contribute more to the field of organizational culture, were they have more focus on the cultural part, even though it's in the context of BD. When analyzing the literature, we discovered that there were many challenges and sometimes solutions being presented in the articles. To make this a useful contribution, we decided to divide this into challenges and strategies for overcoming these.

\subsection{Concept matrix}

The concept matrix was developed to get a figure that illustrate the dimensions discussed in the respective concepts in the literature.

\begin{tabular}{|c|c|c|c|c|c|c|c|}
\hline \multirow[b]{2}{*}{ Articles } & \multicolumn{4}{|c|}{ Big data } & \multicolumn{3}{|c|}{ Organizational culture } \\
\hline & 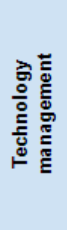 & 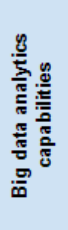 & 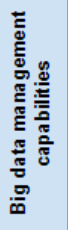 & 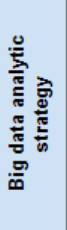 & 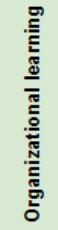 & 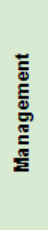 & 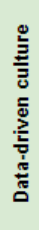 \\
\hline 1. Alharthi et al., 2017 & $\mathrm{x}$ & & & $x$ & & $\mathrm{X}$ & $\mathrm{x}$ \\
\hline 2. Dubey et al., 2019 & & $\mathrm{X}$ & $\mathrm{x}$ & & $x$ & & \\
\hline 3. Ferraris et al., 2018 & & & $\mathrm{x}$ & & & & $\mathrm{x}$ \\
\hline 4. Thiraton et al., 2017 & & $\mathrm{X}$ & $\mathrm{x}$ & & & & $\mathrm{x}$ \\
\hline 5. Dubey et al., 2017 & $\mathrm{x}$ & & $\mathrm{x}$ & & & & $\mathrm{x}$ \\
\hline 6. Ylijoki \& Porras, 2016 & & & & & & & $\mathrm{X}$ \\
\hline 7. Grover et al., 2018 & & & $\mathrm{x}$ & $\mathrm{x}$ & $x$ & $\mathrm{X}$ & \\
\hline 8. Comuzzi \& Patel, 2016 & & & $\mathrm{X}$ & $\mathrm{x}$ & & & \\
\hline 9. Carillo et al., 2018 & & & $x$ & & & & $\mathrm{x}$ \\
\hline 10. Jeble et al., 2018 & $\mathrm{x}$ & $\mathrm{x}$ & $\mathrm{x}$ & & $\mathrm{x}$ & $\mathrm{x}$ & $\mathrm{x}$ \\
\hline 11. Frisk, 2016 & & $\mathrm{X}$ & $\mathrm{x}$ & $\mathrm{X}$ & $\mathrm{x}$ & & $\mathrm{X}$ \\
\hline 12. Shamim et al., 2018 & $\mathrm{x}$ & & & & $\mathrm{x}$ & $\mathrm{x}$ & $\mathrm{x}$ \\
\hline 13.Nguyen, N. 2018 & & & & $\mathrm{x}$ & & & $\mathrm{x}$ \\
\hline 14. Gupta \& George, 2016 & $\mathrm{x}$ & $\mathrm{x}$ & $\mathrm{x}$ & & $x$ & & $\mathrm{x}$ \\
\hline 15. Adrian et al, 2016 & & & $\mathrm{x}$ & $\mathrm{x}$ & & $\mathrm{x}$ & \\
\hline 16. Côrte-real et al., 2019 & $\mathrm{x}$ & $\mathrm{x}$ & $\mathrm{x}$ & $\mathrm{x}$ & & $x$ & $\mathrm{x}$ \\
\hline 17. Mikalef et al., 2017 & & $\mathrm{X}$ & & $x$ & $\mathrm{x}$ & $\mathrm{X}$ & $\mathrm{x}$ \\
\hline 18. Pappas et al., 2018 & & $\mathrm{x}$ & & & $\mathrm{x}$ & & $\mathrm{x}$ \\
\hline 19. Tabesh et al., 2019 & $\mathrm{x}$ & $\mathrm{x}$ & & $\mathrm{x}$ & & $\mathrm{x}$ & $\mathrm{x}$ \\
\hline 20. Cao \& Duan, 2015 & $\mathrm{x}$ & $\mathrm{x}$ & & & & $x$ & $\mathrm{x}$ \\
\hline 21. Duan et al., 2018 & $\mathrm{x}$ & & $\mathrm{x}$ & $\mathrm{X}$ & & $x$ & $\mathrm{x}$ \\
\hline
\end{tabular}

Fig. 1. Concept matrix

\subsection{Organizational culture's impact on big data adoption}

Organizational culture through its assumptions, values, norms, and symbols has a strong impact on various aspects of an organization, such as strategy, structure, and 
processes [10]. This can be related to many of the obstacles that form when an organization is trying to adopt BD. These obstacles are likely to be related to organizational culture and not to data or technology [10]. Recent literature acknowledges this by expressing that organizational culture has a critical role in the success of big data initiatives and is often the main reason why big data initiatives fail, rather than technological factors [6][7][27]. Some go as far as saying that the main challenges for BD management is the organizational culture [4][6]. This means that the impact BD investments has on an organization is usually driven by the culture and not the BD investment itself [9][24], requiring that business analytics must become part of the organizational culture and all employees has to have a positive attitude towards it [28].

\subsection{Challenges of organizational culture in big data adoption}

Most of the literature brings up several specific cultural challenges when adopting BD. The different challenges are categorized within the dimensions of the concept, organizational culture.

In a continuously changing environment, the ability to adapt and reconfigure the resources accordingly is crucial for organizations to maintain a competitive advantage [14]. One of the aspects that influences this ability is organizational learning. Organizational learning refers to the organization's ability to explore, store, share and apply knowledge [29][30]. Due to the rapidly changing market conditions and innovations of new technologies, such as big data, the organizations are challenged to become more agile and adapt to the ever-changing market [14]. Another challenge that is presented is that the organizations need to adapt their organizational culture and adopt new procedures of organizational learning in order to benefit from big data.

Management challenges that may prevent companies from succeeding in BD initiatives include leadership and strategy [4]. Having top management support [7][31][32] and appropriate technical and management skills [32] is also important when trying to acquire success with big data initiatives. The behavior of top managers hat does not value data-driven decision making, will affect the decision patterns at all levels of the organization [11]. Obtaining full benefits from big data does also require aligning existing organizational culture and capabilities across the whole organization [34]. This can be a challenging task for the management. Overcoming leadership focus, harnessing talent, technology management and company culture [4], which are even bigger contributing factors than the technical ones [6], does also present a challenge. Concluding with the words of Gupta \& George [14]: "the intelligence gleaned from data will be of little use to an organization if its managers fail to foresee the potential of newly extracted insights".

A data-driven culture is defined as "the extent to which organizational members (including top-level executives, middle managers, and lower-level employees) make decisions based on the insights extracted from data" [14]. The lack of data-driven culture is among the major reasons for the high failure rate of big data projects [34]. The organizations face the challenges of developing a data-driven culture that manifest a view of data-driven decision making as valuable to decrease the chance of resistance to the development of data-driven culture in order to benefit from big data. Further, 
developing a data-driven culture requires the management to base their decisions on data, rather than instinct [17] and change their attitude towards data-driven decision making [8]. This leads to the several challenges suggested by Ylijoki \& Porras [8], where this challenge often requires the whole organizational culture to change as well as the decision-making process. The organizations ought to change the decision-making process for all members of an organization, including lower-level employees, middlelevel managers and top-level executives [14].

\subsection{Strategies for overcoming challenges of organizational culture in the context of big data.}

Several strategies, techniques, requirements and suggestions to overcome these challenges are presented in the literature and identified in this study. These strategies, techniques, requirements and suggestions is presented within the respective dimension of the concept, organizational culture.

Regarding organizational learning, Bhatt \& Grover [30] and Teece [19] argues that organizations need to make concerted efforts to use their existing knowledge to explore the new knowledge that is aligned with the changing market. Based on this knowledge, organizations can combine it with insight extracted from big data to generate value [14]. Shamim et al. [6] also points at the importance of developing a culture that is strongly change-oriented in order to utilize organizational learning.

First an organization needs to create and foster an organizational culture that is supportive of fact-based decision making and big data analytics. Developing a clear vision of how big data fits with the overall strategy of an organization should help accelerate and solidify the acceptance of this type of organizational culture. Once the vision is formulated, it must be translated into specific organizational processes and initiatives that rely on big data to improve organizational performance [10]. Successful cultural change of this nature can be achieved by documenting, implementing, and communicating a clear organizational vision in relation to big data ensuring top management commitment to this vision, and managing the drivers that influence organizational culture rather than trying to manage culture itself [36]. Adopting a design approach is also a way of enabling organizations to change their decision-making culture and increase the collaboration between different actors and [37] points at the influence of organizational culture in this process. Further, Côrte-real et al. [38] argues that organizations need to align their culture with a data-driven culture with a top-top approach, where strategy is top priority. Then it is followed by managerial and operational factors.

A culture that embraces data- and evidence-driven approaches to business decisions, and governance that delineates responsibility and accountability for data, are both catalysts for BDA value creation [24].

Prior studies in management strategy have identified organizational culture as a source of sustained firm performance [39][40][41]. Developing top management support is one of the critical success factors of big data implementation [32]. Commitment and support among management can significantly mitigate the cultural and technological barriers to BD strategies. This is done by commitment to big data projects that facilitates in generating a data-driven culture by sending signals to everyone in the 
organization [26]. Managers should also build multi skilled teams consisting of data scientists, engineers with technical knowledge and translators who are familiar with both technical and business languages. This can help managers interpret the generated insights before transforming them into business decisions [42]. This practice can over time create a rich culture of open communication that will help addressing BD challenges [11]. Further, aligning the existing organizational culture and capabilities across the whole organization [34] is another one. Companies must not only hire scientists who can translate big data into useful business information in order to have success. There also need to be a change in the managerial mindset, re-orient it to having a more digital and data-driven culture focus [34]. Managers must also "attend to the big data era" [43], resulting in becoming skilled in its methods and analytics, and learn to explore big data to develop the needed competitive advantage. Companies that manage to develop leadership teams with clear big data strategies, have clear goals, and can articulate the business case, would increase the likelihood of succeeding. Those teams can define what success is and have the ability to ask the right questions [24].

\section{Discussion}

The rise of big data has made the field very interesting for society, individuals and organizations. Organizations especially, are very interested in the potential big data can bring them, mostly because of the ever-increasing competition in today's marked. Publications discussing organizational culture's effect on big data adoption is still in its early stage. This can be seen in this paper, where the oldest papers are from 2015. Our findings revealed that organizational culture is still a somewhat new aspect in the field of big data, the reason being that the majority of the papers only mentioned organizational culture as an important factor in the adoption of big data, and did not have it as one of the main focuses areas. Our findings also showed that the literature was very supportive of the notion that organizational culture played a critical role for organizations when trying to succeed with big data adoption. This demonstrated that there is a gap in the research about exactly how much organizational culture effect the big data adoption, and how one can strategically plan to cultivate an organizational culture that is fully supportive of big data, which will increase the benefit an organization get from big data.

Our findings revealed that a gap between the big data analytics investments and the ability to effectively derive business insights and increase the performance of the organization [43]. The impact of big data investments is predominantly driven by culture and not the BDA investments themselves [23]. Lack of such culture could be detrimental when trying to identify and generate the potential value big data has to offer [24].

Further, it is argued that being change-oriented and having focus on the existing knowledge is important in order to exploit new knowledge and organizational learning. The literature often mentions the leadership is an important factor for organizational learning, where the influence of the management and leadership is crucial. The 
organizations should be in constant change and be positive towards changing their procedures and routines accordingly to the changing environment [45][34].

Organizations need to develop a data-driven culture in order to benefit from data. Duan et al. [46] also suggest that there is clear evidence that demonstrates the important role of data-driven culture as an emergent organizational culture in the context of big data. The literature suggested that the leadership must develop a vision for the change and implement procedures and routines that supports the vision. Even though organizations develop a clear vision, organizations tend to have less focus on the end state and goal, which may result in challenges regarding initiating the changes. This is often due to the focus on resource efficiency, which organizations may not predict [17]. Even though the cultural change must be initiated from the top leadership, the lower-level employees and medium-level managers must have a positive attitude towards the change.

Developing top management support was also demonstrated to be of great importance in our findings [31]. Organizational culture was also shown to be a source of sustained firm performance [38][40][41]. Aligning the existing organizational culture and its capabilities across the whole organization [34], while also having management educated in big data 's methods and analytics, is needed. The management also need to change their managerial mindset, reorienting it to a more digital and data-driven culture focused one [34].

This study has some limitations, like any other systematic literature review. To avoid being biased in the selection process, we developed a research question, as well as inclusion and exclusion criteria. This may result in some relevant papers were excluded due the failure of meeting the requirements. Additionally, we limited the literature to conference proceedings and peer-reviewed articles which may leave out some useful research within this field.

\section{Conclusion}

The results showed that there is literature out there in support of the positive impact organizational culture has on $\mathrm{BD}$. However, there is not many papers measuring this exactly, so a future study with the focus of measuring organizational culture and its impact on big data in organizations would be a valuable contribution. Furthermore, there are a need of research regarding changing the culture in order to align the culture with big data solutions.

The results of this review have implications for practitioners where organizations can identify the specific challenges that are brought with big data adoption. Additionally, there is several techniques, strategies or guidelines on how it can be combated. This study has also academic value where It summarizes the relevant literature that is discussing $\mathrm{BD}$ and organizational culture, which is a relatively new topic combined, but very timely and critical for understanding the cultural impact on big data adoption. Because of this topic being relatively new, some of the conclusion to draws from today's literature can be somewhat vague and hard for organizations to implement, this illustrates further that there is more research needed to be done on this topic. 


\section{Acknowledgments}

This work has received funding from the European Union's Horizon 2020 research and innovation programme, under the Marie Sklodowska-Curie Grant Agreements Nos. 751550 .

\section{References}

1. Weill, P. And Woerner, S.L. (2015). Thriving in an increasingly digital ecosystem. MIT Sloan Management Review, 56(4), 27-34.

2. Pappas, O. I., Mikalef, P., Giannakos, N. M., Krogstie, J. \& Lekakos, G. (2018). Big data and business analytics ecosystems: paving the way towards digital transformation and sustainable societies. Information Systems and e-Business Management, 16(3), 479-491. https://doi.org/10.1007/s10257-018-0377-z

3. Mikalef, P., Pappas, O. I., Krogstie, J. \& Giannakos, M. (2017). Big data analytics capabilities: a systematic literature review and research agenda. Information Systems and e-Business Management. doi: 10.1007/s10257-017-0362-y

4. McAfee, A. and Brynjolfsson, E. (2012). Big data: The management revolution. Harvard business review, 90, 61-67

5. Manyika, J., Chui, M., Brown, B., Bughin, J., Dobbs, R., Roxburgh, C. \& Byers, A.(2011). Big data: The next frontier for innovation, competition and productivity. Available at: https://www.mckinsey.com/business-functions/digital-mckinsey/our-insights/big-data-thenext-frontier-for-innovation

6. Shamim, S., Zeng, J., Shariq, M. S. \& Khan, Z. (2018). Role of big data management in enhancing big data decision-making capability and quality among Chinese firms: A dynamic capabilities view. Information \& Management. https://doi.org/10.1016/j.im.2018.12.003

7. LaValle, S., Lesser, E., Shockley, R. \& Hopkins, M. (2011). Big data, analytics and the path from insight to value. MIT Sloan Management, 52(2), 21-32.

8. Ylijoki, O. \& Porras, J. Conceptualizing big data: Analysis of case studies. Intelligent systems in accounting, finance and management, 23, 295-310. doi: 10.1002/isaf.1393

9. Thirataon, U., Wieder, B., Matolcsy, Z. \& Ossimitz, L-M. (2017). Big Data, Analytic Culture and Analytic-Based Decision Making - Evidence from Australia. Procedia Computer Science, 121, 775-783. https://doi.org/10.1016/j.procs.2017.11.100

10. Alharti, A., Krotov, V. \& Bowman, M. (2017). Addressing barriers to big data. Business Horizons, 60, 285-292. http://dx.doi.org/10.1016/j.bushor.2017.01.002

11. Tabesh, P., Mousavidin, E. \& Hasani, S. (2019). Implementing big data strategies: A managerial perspective. Business Horizons. doi: https://doi.org/10.1016/j.bushor.2019.02.001

12. Nguyen, L, T. (2018). A Framework for Five Big V's of Big Data and Organizational Culture in Firms. Proceedings of the IEEE International Conference on Big Data (Big Data), Seattle, USA

13. Mazzei, M. J., \& Noble, D. (2017). Big data dreams: A framework.

14. Gupta, M. \& George, F. J. (2016). Toward the development of a big data analytics capability. Information \& Management, 53, 1049-1064. http://dx.doi.org/10.1016/j.im.2016.07.004

15. Iivari, J \& Huisman, M. (2007). The relationship between organizational culture and the deployment of systems development methodologies. MIS Quarterly, 31(1), 35-58.

16. . Dowling, G. (1993). Developing your company image into a corporate asset. Long Range Planning, 26(2), 101-109. 
17. Dubey, R., Gunaasekaran, A., Childe, J. S., Papadopoulos, T., Luo, Z., Wamba, F. S. \& Roubaud, A. (2017). Can big data and predictive analytics improve social and environmental sustainability? Technological Forecasting \& Social Change. http://dx.doi.org/10.1016/j.techfore.2017.06.020

18. Dubey, R., Gunasekaran, A., Childe, J. S., Roubaud, D., Wamba, F. S., Giannakis, M. \& Foropon, C. (2019). Big data analytics and organizational culture as complements to swift trust and collaborative performance in the humanitarian supply chain. Internal Journal of Production Economics, 120, 120-136. https://doi.org/10.1016/j.ijpe.2019.01.023

19. Jeble, S., Dubey, R., Childe, J. S., Papadopoulos, T., Roubaud, D. \& Prakash, A. (2018). Impact of big data and predictive analytics capability on supply chain sustainability. The International Journal of Logistics Management, 29(2), 513-538. https://doi.org/10.1108/IJLM-05-2017-0134

20. Teece, D., Pisano, G. and Shuen, A. (1997). Dynamic capabilities and strategic management. Strategic Management Journal, 18(7), 509-533.

21. Kiron, D., Prentice, P. K. and Ferguson, R. B. (2012). Innovating with analytics. (cover story). MIT Sloan Management Review, 54 (1), 47-52.

22. Cao, G. \& Duan, Y. (2015). The Affordances of Business Analytics for Strategic DecisionMaking and Their Impact on Organizational Performance. Proceedings of the Pacific Asia Conference on Information systems, 2015, Singapore.

23. Comuzzi, M \& Patel, A. (2016). How organisations leverage Big Data: a maturity

24. Grover, V., Chiang, L. H. R., Liang, P-T. \& Zhang, D. (2018). Creating Strategic Business Value from Big Data Analytics: A Research Framework. Journal of Management Information Systems, 35(2), 388-432. doi: 10.1080/07421222.2018.1451951

25. Kitchenham, B. and Charters, S. (2007). Guidelines for performing systematic literature reviews in software engineering. Keele University and University of Durham, EBSE technical report.

26. 26. Webster, J. and Watson, R. (2002). Webster and Watson literature review. MIS Quarterly, 26(2).

27. Adrian, C., Abdullah, R., Atan, R. \& Jusoh, Y. (2016). Towards Devloping Strategic Assessment Model for Big Data Implementation: A Systematic Literature Review. International Journal of Advances in Soft Computing and its Applications, 8(3).

28. Müller, S.D. and Jensen, P. (2017). Big data in the Danish industry: application and value creation. Business Process Management Journal, 23(3), 645-670.

29. Grant, R. (1996). Toward a knowledge-based theory of the firm. Strategic Management Journal, 17(2), 109-122.

30. Bhatt, G. and Grover V. (2005). Types of Information Technology Capabilities and Their Role in Competitive Advantage: An Empirical Study. Journal of Management Information Systems, 22(2), 253-277.

31. Chen, D. Q., Preston, D. S., \& Swink, M. (2015). How the use of big data analytics affects value creation in supply chain management. Journal of Management Information Systems, 32(4), 4-39.

32. Halaweh, M. and El Massry, A. (2015). Conceptual Model for Successful Implementation of Big Data in Organizations. Journal of International Technology and Information Management, 24(2), 21-29.

33. Waller, M.A. and Fawcett, S.E. (2013). Data science, predictive analytics, and big data: a revolution that will transform supply chain design and management. Journal of Business Logistics, 34(2), 77-84. 
34. Ferraris, A., Mazzoleni, A., Devalle, A. \& Couturier, J. (2019). Big data analytics capabilities and knowledge management: impact on firm performance. Management Decision. https://doi.org/10.1108/MD-07-2018-0825

35. Ross, J. W., Beath, C. M., \& Quaadgras, A. (2013). You may not need big data after all. Harvard business review. available at: https://hbr.org/2013/12/you-may-not-need-big-dataafter-all

36. Rogers, P., Meehan, P. \& Tanner, S. (2006). Building a winning culture [White paper]. Bain and Company. Available at: http://growthtrilogy.com/bainweb/PDFs/cms/Public/BB_Building_winning_culture.pdf

37. Frisk, E. J. \& Bannister, F. (2017). Improving the use of analytics and big data by changing the decision-making culture: A design approach. Management Decision, 55(10), 2074-2088. https://doi.org/10.1108/MD-07-2016-0460

38. Corte-Real, N., Ruivo, P., Oliveira, T. \& Popovic, A. (2019). Unlocking the drivers of big data analytics value in firms. Journal of Business Research, 97, 160-173. https://doi.org/10.1016/j.jbusres.2018.12.072

39. Barney, J.B. (1995). Looking inside for competitive advantage. Academy of Management, 9(4).

40. Teece, D. (2015). Intangible assets and a theory of heterogeneous firms. In Bounfour, A. and Miyagawa, T. (Eds), Intangibles. Market failure and innovation performance, Springer, Cham.

41. Barney, J.B. (1986). Organizational Culture: Can It Be a Source of Sustained Competitive Advantage. Academy of Management, 11(3).

42. Mayhew, H., Saleh, T., \& Williams, S. (2016). Making data analytics work for you-Instead of the other way around. McKinsey Quarterly. Available at https://www.mckinsey.com/business-functions/digital-mckinsey/our-insights/making-data-analytics-work-foryou-instead-of-the-other-way-around

43. Mishra, D., Luo, Z., Jiang, S., Papadopoulos, T. and Dubey, R. (2017). A bibliographic study on big data: concepts, trends and challenges. Business Process Management Journal, 23(3), 555-573.

44. Carillo, A. D. K., Galy, N., Guthrie, C. \& Vanhems, A. (2018). How to turn managers into data-driven decision makers: Measuring attitudes towards business analytics. Business Process Management Journal. https://doi.org/10.1108/BPMJ-11-2017-0331

45. Kor, Y.Y, Mahoney, J,T. \& Michael, S.C. (2007). Resources, Capabilities and Entrepreneurial Perceptions. Journal of Management Studies, 44(7), 1187-1212.

46. Duan, Y., Cao, G. and Edwards, J. S. (2018). Understanding the impact of business analytics on innovation. European Journal of Operational research. doi: https://doi.org/10.1016/j.ejor.2018.06.021 